Check for updates

Montreal

Cite this as: $B M J$ 2021;374:n1786 http://dx.doi.org/10.1136/bmi.n1786 Published: 14 July 2021

\title{
Covid-19: Regulators warn that rare Guillain-Barré cases may link to J\&J and AstraZeneca vaccines
}

\section{Owen Dyer}

The Johnson \& Johnson (J\&J) coronavirus vaccine may be linked to rare but serious cases of Guillain-Barré syndrome, an autoimmune disorder in which immune cells attack the nervous system, the US Food and Drug Administration has warned. ${ }^{1}$

The FDA's warning on 12 July came three days after the European Medicines Agency's safety committee recommended adding a Guillain-Barré warning to the labelling of the AstraZeneca vaccine. ${ }^{2}$

The EMA committee also warned on 9 July that people who have previously had capillary leak syndrome should seek a vaccine other than J\&J. ${ }^{3}$ This advice was based on three reported cases that occurred within two days of vaccination. One of the patients had a history of the syndrome. Two of the three subsequently died. Swelling of the extremities is a potential warning sign of this condition.

About 19 million people worldwide have received the J\&J vaccine, also sometimes called the Janssen vaccine.

\section{mRNA vaccines}

The EMA also issued a warning about the mRNA vaccines made by Pfizer and Moderna. These vaccines' product information should list pericarditis and myocarditis as new side effects, the agency said. ${ }^{4}$

A similar labelling change was already ordered by the FDA on 25 June. ${ }^{5}$ The two agencies found the same pattern: the risk of pericarditis and myocarditis was heavily concentrated in young men, particularly after the second dose, typically within six days of mRNA vaccine administration.

Europe's reporting system has identified 145 cases of myocarditis and 138 cases of pericarditis among 177 million doses given of the Pfizer vaccine. It has detected 19 cases of each condition among 20 million doses given of Moderna's.

The US vaccine adverse event reporting system has found 1226 cases of pericarditis or myocarditis among roughly 300 million mRNA doses. The median age of the women affected was 30 , while in men it was 24 . But the group with the most elevated risk was teenage males.

By age 30 the risk of developing pericarditis or myocarditis in the days after mRNA vaccination is already much lower. Once a recipient is over 50 the vaccines seem to bring no extra risk of these conditions.

Among people aged 12-39 males were at much higher risk, with 32 cases in a million doses reported versus 4.7 cases in a million doses in women. The preponderance of males was greatest after the second dose, when two of every three cases occurred. ${ }^{6}$
Of 323 cases of pericarditis or myocarditis in people aged under 30 reviewed by the US Centers for Disease Control and Prevention, 309 were admitted to hospital and nine remain there, two in intensive care. None of these patients has died.

\section{Vaccine uptake}

While the FDA's warnings about the mRNA vaccines drew little public notice in the United States, the warning linking Guillain-Barré syndrome to the J\&J vaccine has made headlines and could further depress uptake of a vaccine that has been a clear second favourite with the public since its use was temporarily halted over concerns about thrombocytopenia.

The single dose, easily stored J\&J vaccine was eagerly awaited by public health providers, but to date it has accounted for only 13 million of 335 million vaccine doses given in the US. Those 13 million doses have been accompanied by 100 case reports of Guillain-Barré syndrome, the FDA said, of which 95 required hospital admission and one has ended in death. Men aged over 50 showed the greatest risk, and cases typically appeared about two weeks after vaccination.

Neither the EMA nor the FDA is yet prepared to declare a certain causal link between the J\&J or AstraZeneca vaccine and Guillain-Barré syndrome. Cases of the syndrome appearing after vaccination with the AstraZeneca vaccine, as well as those reviewed by the EMA, have been reported in England ${ }^{7}$ and India. ${ }^{8}$

US Food and Drug Administration. Letter granting emergency use authorization amendment, Janssen covid-19 vaccine. 12 Jul 2021. https://www.fda.gov/media/150723/download

2 European Medicines Agency. Meeting highlights from the Pharmacovigilance Risk Assessment Committee (PRAC) 5-8 July 2021. 9 Jul 2021. https://www.ema.europa.eu/en/news/meeting-highlights-pharmacovigilance-risk-assessment-committee-prac-5-8-july-2021

3 European Medicines Agency. EMA advises against use of covid-19 vaccine Janssen in people with history of capillary leak syndrome. 9 Jul 2021 https://www.ema.europa.eu/en/news/ema-advises-against-use-covid-19vaccine-janssen-people-history-capillary-leak-syndrome

4 European Medicines Agency. Comirnaty and Spikevax: possible link to very rare cases of myocarditis and pericarditis. 9 Jul 2021. https://www.ema.europa.eu/en/news/comirnaty-spikevax-possible-linkvery-rare-cases-myocarditis-pericarditis

5 US Food and Drug Administration. Letter granting emergency use authorization amendment, Moderna covid-19 vaccine. 25 Jun 2021. https://www.fda.gov/media/150723/download

6 US Centers for Disease Control and Prevention. Covid-19 vaccine safety updates: Advisory Committee on Immunization Practices (ACIP). 23 Jun 2021. https://www.cdc.gov/vaccines/acip/meetings/downloads/slides-2021 06/03-COVID-Shimabukuro-508.pdf

Allen CM, Ramsamy S, Tarr AW, et al. Guillain-Barré syndrome variant occurring after SARS-CoV-2 vaccination. Ann Neurol 2021. https://onlinelibrary.wiley.com/doi/10.1002/ana.26144

8 Maramattom BV, Krishnan P, Paul R, et al. Guillain-Barré Syndrome following ChAdOx1-S/nCoV-19 vaccine. Ann Neurol 2021. https://onlinelibrary.wiley.com/doi/10.1002/ana.26143 
This article is made freely available for use in accordance with BMI's website terms and conditions for the duration of the covid-19 pandemic or until otherwise determined by BMJ. You may use, download and print the article for any lawful, non-commercial purpose (including text and data mining) provided

that all copyright notices and trade marks are retained. 